\title{
Reativações Neotectônicas na Zona de Cisalhamento do Rio Paraíba do Sul (Sudeste do Brasil)
}

\section{Neotectonic Reactivations in the Rio Paraíba do Sul Shear Zone (Southeastern Brazil)}

\author{
Thiago Pinto da Silva (thiagopintosilva@yahoo.com.br) e Claudio Limeira Mello (limeira@geologia.ufri.br) \\ Departamento de Geologia - Instituto de Geociências - UFRJ \\ Av. Athos da Silveira Ramos 274 - Bloco G, CEP 21941-916, Rio de Janeiro, RJ, BR
}

Recebido em 23 de abril de 2010; aceito em 18 de janeiro de 2011

\section{RESUMO}

O presente trabalho tem como objetivo investigar a atuação de mecanismos neotectônicos na região da Zona de Cisalhamento do Rio Paraíba do Sul, importante feição geotectônica adjacente ao segmento central do Rift Continental do Sudeste do Brasil, e áreas adjacentes. A metodologia empregada baseia-se na integração de análises morfoestratigráficas e de dados estruturais, enfatizando a identificação de pares falha/estria afetando sedimentos cenozoicos e as rochas do embasamento alteradas, no intuito de caracterizar os campos de esforços neotectônicos. A partir das relações entre diferentes padrões de fraturamento e as unidades geológicas afetadas, e da percepção de superposição de estrias em um mesmo plano de falha, foi possível o reconhecimento de três fases neotectônicas, correlacionáveis a eventos descritos para o Sudeste do Brasil: transcorrência sinistral E-W, de idade miocênica; transcorrência dextral E-W, datada do limite Pleistoceno-Holoceno; e regime distensivo NW-SE, holocênico. As fases neotectônicas identificadas têm forte relação com a reativação das anisotropias estruturais preexistentes.

Palavras-chave: Neotectônica; Sudeste do Brasil; Zona de Cisalhamento do Rio Paraíba do Sul.

\begin{abstract}
This study aims to investigate neotectonic activities in the region of the Rio Paraiba do Sul Shear Zone, an important geotectonic feature adjacent to the central segment of the Continental Rift of Southeastern Brazil, and contiguous areas. The methodology used in this work is based on the integration of morphostratigraphic and structural data analysis. The analysis of the fault/striae pairs observed in Cenozoic sediments and weathered basement rocks was highlighted in order to characterize neotectonic stress fields. The relationship among the different fracturing patterns, geologic units affected by these events and overlapping patterns of striae on a same fault plain lead to the characterization of three neotectonic stages which could be correlated to the neotectonic events described for the Southeastern Brazil: E-W left-lateral transcurrent stage (Miocene); E-W right-lateral transcurrent stage (Pleistocene/Holocene); and NW-SE extensional stage (Holocene). These neotectonic stages have a strong relationship with the reactivation of the preexisting structural anisotropies.
\end{abstract}

Keywords: Neotectonics; Southeastern Brazil; Rio Paraíba do Sul Shear Zone. 


\section{INTRODUÇÃO}

Diversos estudos têm apresentado quadros que sintetizam a evolução tectonossedimentar da região Sudeste do Brasil durante o Cenozoico, mostrando, particularmente, a atuação de mecanismos neotectônicos (Riccomini, 1989; Riccomini et al., 1989; Salvador, 1994; Salvador e Riccomini, 1995; Mello, 1997; Mello et al., 1999; Riccomini e Assumpção, 1999; Ferrari, 2001; Modenesi-Gauttieri, Hiruma, Riccomini, 2002; Sarges, 2002; Albuquerque, 2004; Riccomini, Sant'Anna, Ferrari, 2004; Sanson, 2006; Gontijo-Pascutti et al., 2010). Segundo Hasui (1990), estes mecanismos neotectônicos enquadram-se em um modelo de tectônica ressurgente, ou seja, aproveitando-se parcialmente de planos de fraqueza desenvolvidos durante fases tectônicas anteriores.

A principal área estudada a respeito da Neotectônica no sudeste do Brasil corresponde à região do médio vale do rio Paraíba do Sul, onde se destaca um importante conjunto de bacias sedimentares terciárias (bacias de Taubaté, Resende e Volta Redonda), correspondendo ao segmento central do Rift Continental do Sudeste do Brasil (RCSB). Configura um hemi-graben limitado pelas serras do Mar e da Mantiqueira - horsts cujos traços morfológicos representam um conjunto topográfico alçado que acompanha os limites do Rift Continental do Sudeste do Brasil (IBGE, 1997).

Esta importante feição geotectônica envolve, de acordo com Riccomini (1989) e Riccomini, Sant'Anna e Ferrari (2004), cinco fases tectônicas:

- $1^{\text {a }}$ Fase (Eoceno-Oligoceno) - distensão NNW-SSE, imposta pelo basculamento termomecânico da bacia de Santos, que teria levado à formação de uma depressão contínua, pela reativação de antigas zonas de cisalhamento brasilianas como falhas lístricas com caimento para o Oceano Atlântico.

- $2^{\mathrm{a}}$ Fase (Neógeno) - transcorrência sinistral E-W, primeira fase de deformação do RCSB, provavelmente oligocênica a neogênica, com distensão NW-SE e, localmente, compressão NE-SW.

- $3^{\text {a }}$ Fase (Pleistoceno/Holoceno) - transcorrência dextral E-W, com compressão NW-SE.

- $4^{\mathrm{a}}$ Fase (Holoceno) - distensão NW(WNW)-SE(ESE).

- $5^{\text {a }}$ Fase (Holoceno, subatual) - compressão E-W, caracterizada por famílias de juntas conjugadas de direção ENE e WNW, indicando campo de esforços que perduraria até o presente.

Em continuidade ao segmento central do RCSB, o rio Paraíba do Sul apresenta um traçado retilíneo adaptado a um expressivo lineamento tectônico, com cerca de $260 \mathrm{~km}$ de extensão e até $10 \mathrm{~km}$ de largura, e direção principal
ENE. Denominado por Almeida, Hasui e Carneiro (1975) como Lineamento de Além Paraíba, foi reconhecido por Dayan e Keller (1990) como Zona de Cisalhamento do Rio Paraíba do Sul (ZCRPS), associada a uma deformação dúctil, formadora de rochas miloníticas.

O presente estudo tem como objetivo realizar uma investigação neotectônica na área da Zona de Cisalhamento do Rio Paraíba do Sul e áreas montanhosas adjacentes, abrangendo uma seção transversal às feições geomorfológicas mais marcantes da região Sudeste do Brasil - serras do Mar e da Mantiqueira, e depressão interplanáltica do rio Paraíba do Sul. A principal motivação para o este estudo foi avaliar a continuidade dos campos de paleotensões neotectônicas em área adjacente ao segmento central do RCSB e marcada por uma importante feição geotectônica, muito expressiva sob os pontos de vista geológico e geomorfológico.

\section{CARACTERIZAÇÃO DA ÁREA DE ESTUDO}

\section{Localização e acessos}

A área de estudo compreende parte dos estados do Rio de Janeiro e de Minas Gerais (Figura 1), na porção coberta pelas cartas topográficas (IBGE, 1:50.000) Miguel Pereira, Paraíba do Sul, Matias Barbosa e Juiz de Fora.

A principal via de acesso à área de estudo é a BR-040, que liga o Rio de Janeiro a Belo Horizonte, passando por Três Rios (RJ) e Juiz de Fora (MG). Existem diversas rodovias estaduais e federais que atravessam a área de estudo nos dois estados. No Rio de Janeiro, as principais são: a RJ-125, que passa pelos municípios de Miguel Pereira e Paty do Alferes; a RJ-123; a BR-393, que, no trecho abrangido pela área de estudo, acompanha o curso do rio Paraíba do Sul; e a RJ-151. Em Minas Gerais, podem ser citadas: a MG-353, que liga o município de Juiz de Fora a Santa Bárbara do Monte Verde, a oeste, e a Coronel Pacheco, a leste; e a BR-267, de Juiz de Fora para Lima Duarte.

\section{Geologia regional}

A área de estudo está inserida na Província Mantiqueira (Almeida et al., 1977), na Faixa Móvel Ribeira, com origem relacionada à orogenia neoproterozoica Brasiliana-Pan Africana.

De acordo com Heilbron et al. (2004), com base em diversos outros trabalhos, três associações litológicas constituem o embasamento da Faixa Ribeira na área de estudo: a. ortognaisses migmatíticos, granitoides e metabasitos, com idades arqueanas $(2,8-2,7 \mathrm{Ga})$ a paleoproterozoicas $(2,2$ 2,0 Ga), pertencentes ao Complexo Mantiqueira; b. ortogranulitos arqueanos (situados nas proximidades de Juiz de 


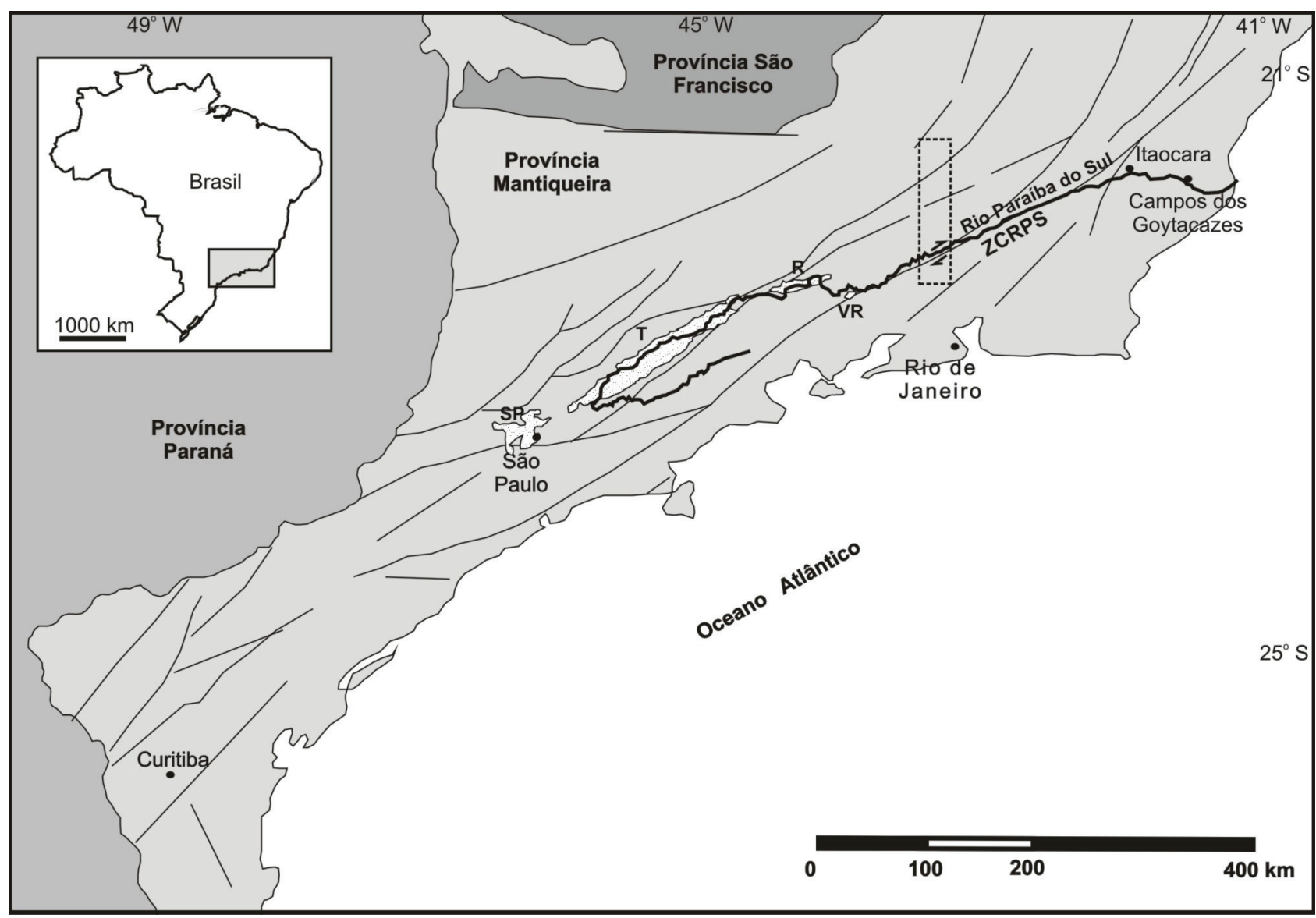

Figura 1. Principais falhas (e cinturões miloníticos associados) da Província Mantiqueira (modificado de Sadowski e Campanha, 2004) e bacias sedimentares que compõem o segmento central do Rift Continental do Sudeste do Brasil (SP: bacia de São Paulo; T: bacia de Taubaté; R: bacia de Resende; VR: bacia de Volta Redonda - segundo Riccomini, 1989). Em destaque a Zona de Cisalhamento do Rio Paraíba do Sul (ZCRPS). A área de estudo (área retangular tracejada) corresponde às cartas topográficas (1:50.000, IBGE) Miguel Pereira, Paraíba do Sul, Matias Barbosa e Juiz de Fora.

Fora) e paleoproterozoicos, que integram o Complexo Juiz de Fora, além de granitoides cálcio-alcalinos e granitos $(2,14$ e 2,07 Ga), e metabasitos que podem ser agrupados em uma suíte formada por rochas alcalinas $(2,22-2,13 \mathrm{Ga})$ e outra formada por rochas toleíticas $(2,4 \mathrm{Ga})$; c. granitoides tonalítico-granodioríticos, com enclaves de rochas metaultramáficas, metamáficas e cálcio-silicáticas (Complexo Quirino, com idades de 2,19 e 2,17 Ga).

Sobre as rochas do embasamento, encontram-se sucessões metassedimentares neoproterozoicas relacionadas à Megassequência Andrelândia, na porção norte da área de estudo, englobando paragnaisses bandados com intercalações de anfibolitos, quartzitos, filitos, xistos e rochas cálcio-silicáticas, e ao Grupo Paraíba do Sul, composto por paragnaisses com intercalações carbonáticas e cálcio-silicáticas.
Durante a Orogenia Brasiliana, as rochas listadas acima foram deformadas e o magmatismo associado é representado por: ortognaisses tonalíticos a graníticos, cálcio-alcalinos, com corpos gabroicos associados, correspondentes às rochas do Arco Magmático Rio Negro (790 - 620 Ma); e leucogranitos e/ou granada charnockitos (ca. $580 \mathrm{Ma}$ ) e biotita granitos (ca. $560 \mathrm{Ma}$, tipo Serra dos Órgãos).

Ocorrem ainda, na área de estudo, diques de rocha básica, constituídos principalmente por diabásio e microgabro, com textura afanítica e fanerítica fina, respectivamente, relacionados ao magmatismo cretáceo, cortando as rochas de idade pré-cambriana, encaixadas em zonas de fraturamento.

Calderano e Lemos (1998), em estudo no município de Paty do Alferes, na porção sul da área de estudo, ressal- 
taram a presença de sedimentos argilo-arenosos, profundamente pedogeneizados, em inconformidade com o embasamento, que podem ser correlacionáveis, em idade, ao Terciário/Quaternário. Segundo os autores, esses sedimentos ocorrem distribuídos ao longo de toda área e apresentam espessuras de até $10 \mathrm{~m}$, dispostos sobre uma camada de cascalhos arredondados e quartzosos, sendo associados a topos aplainados, em situação geomorfológica que sugere representarem restos preservados de antigas superfícies sedimentares. Machado Filho et al. (1983) reconheceram tais depósitos em escala regional.

Sedimentos argilo-arenosos e areno-argilosos, de natureza coluvial e aluvial, de idade quaternária, ocorrem em toda a área de estudo, preenchendo fundo de vales e ocupando áreas ao sopé de encostas.

\section{A Zona de Cisalhamento do Rio Paraíba do Sul}

Uma característica marcante da área de estudo é o trecho em que o rio Paraíba do Sul apresenta um traçado retilíneo, mostrando-se adaptado a um expressivo lineamento estrutural que se destaca na paisagem da depressão topográfica do rio Paraíba do Sul, entre Volta Redonda (RJ) e Itaocara (RJ) - Figura 1.

Essa feição foi descrita primeiramente por Almeida, Hasui e Carneiro (1975), que a denominou como Lineamento de Além Paraíba. Possui cerca de 260 km de extensão e até $10 \mathrm{~km}$ de largura, com gnaisses milonitizados e extremamente recristalizados, com direção principal ENE. Estes autores afirmaram que esta estrutura apresenta uma evolução polifásica, onde a derradeira fase de atividade é tardibrasiliana, processando-se em nível crustal pouco profundo, dando origem a estruturas cataclásticas nos milonitos.

Campanha (1981) a interpreta como uma megazona de cisalhamento, com movimentação transcorrente dextral de rejeito desconhecido, com a existência de esforços compressivos para a deformação.

Dayan e Keller (1990), a partir de estudo realizado nas cercanias do município de Três Rios (RJ), destacaram a existência de extensas faixas alinhadas que exibem feições de intensa concentração de deformações dúcteis localizadas, identificadas como zonas de cisalhamento. Assim, denominaram o Lineamento de Além Paraíba como Zona de Cisalhamento do Rio Paraíba do Sul (ZCRPS), em função da simetria de estruturas em relação à zona central do lineamento, ocupada pelo rio Paraíba do Sul. Estes autores reconheceram ainda que, na medida em que se aproxima da zona de cisalhamento central, modificam-se as características das rochas, pois a foliação gnáissica torna-se mais finamente espaçada e é acompanhada por uma progressiva verticalização da atitude do bandamento metamórfico.
Correa Neto et al. (1993) mostraram a existência de rochas de diferentes graus de deformação, onde a foliação milonítica bordeja lentes de rochas relativamente menos deformadas, formando um padrão anastomótico, com eixos maiores em extremo paralelismo com o rio Paraíba do Sul. Além disso, comprovaram a presença de estruturas-em-flor positivas, típicas em áreas com regime transpressivo, responsáveis pelo soerguimento de rochas de níveis crustais inferiores.

Correa Neto e Dayan (1996) ratificaram o caráter dextral da ZCRPS, introduzido por Campanha (1981), e mostraram que, no sentido NE, ao longo da ZCRPS, níveis crustais cada vez mais profundos são expostos.

Apesar de Sadowski e Campanha (2004) reconhecerem que a abertura do Atlântico aproveitou a existência de antigas linhas de fraqueza existentes no Sudeste do Brasil para a geração de feições geomorfológicas, nenhum dos autores acima citados identificou indícios de reativações tectônicas na ZCRPS em tempos mais recentes.

\section{Geomorfologia regional}

Gatto et al. (1983) reconheceram dois domínios geomorfológicos na região: o Domínio das Faixas de Dobramentos Remobilizados, caracterizado pelo nítido controle estrutural sobre a morfologia atual, representado por extensas linhas de falha e escarpas de grande dimensão; e o Domínio do Escudo Exposto, que revela características morfoestruturais de estabilidade, marcado por blocos de relevos alçados, posteriormente atingidos por estágios sucessivos de erosão.

O Domínio das Faixas de Dobramentos Remobilizados abrange quase a totalidade da área de estudo, desde o reverso da Serra do Mar até as proximidades da escarpa da Serra da Mantiqueira, sendo representado pelas unidades:

a. Serra dos Órgãos, que apresenta relevo composto por escarpas escalonadas e festonadas, com seu reverso constituindo um conjunto topográfico definido por lineamentos de vales estruturais e cristas serranas. Suas cotas topográficas podem variar de cerca de $600 \mathrm{~m}$ a mais de $2.200 \mathrm{~m}$, em locais restritos. A drenagem se desenvolve obedecendo a nítido controle estrutural;

b. Alinhamento de Cristas do Paraíba do Sul, que corresponde a um trecho do vale do rio Paraíba do Sul cujas feições refletem o alto controle geológico, disposto em um feixe de falhas com orientação aproximadamente NE-SW. A presença de relevo de colinas alinhadas, variando de 300 a $900 \mathrm{~m}$ de altitude, reflete fortemente as estruturas e litologias locais. Outra característica peculiar dessa unidade é a distribuição das principais formas de acumulação ao lon- 
go do rio Paraíba do Sul, originando amplas planícies fluviais, em cotas altimétrica normalmente inferiores a $300 \mathrm{~m}$;

c. Serranias da Zona da Mata Mineira, identificada por relevos de formas alongadas, marcados por escarpas adaptadas a falhas, sulcos estruturais, grandes linhas de cumeada e cristas simétricas alinhadas. Os rios, nesta unidade, geralmente formam pequenos terraços e planícies.

O Domínio do Escudo Exposto é representado pela Unidade Planalto de Campos das Vertentes, ocorrendo em uma porção da área de estudo a norte de Juiz de Fora. Configura um compartimento planáltico elevado, com altitudes entre 400 e $1.300 \mathrm{~m}$, intensamente dissecado, resultando em uma paisagem típica de "mares de morros".

Silva (2002), com base na utilização da metodologia de desnivelamentos altimétricos, definiu dois Domínios Morfoestruturais, através da identificação de grandes conjuntos de formas de relevo que são associados às principais estruturas geológicas regionais: a. Domínio Morfoestrutural Planalto Atlântico, representado na área de estudo pelas unidades Planalto e Escarpas da Serra da Mantiqueira e Planalto e Escarpas da Serra dos Órgãos, que se configuram como conjuntos de degraus escarpados e degraus/ serras reafeiçoados, com orientação geral NE-SW, com altitudes de 700 a 1.800 m; b. Domínio Morfoestrutural Depressões Tectônicas Cenozoicas, representado pela Unidade Alinhamento de Cristas do Paraíba do Sul, que reflete fortemente a estrutura e as litologias locais, com a orientação nítida de colinas e morros na direção NE-SW, destacando-se nas cartas geomorfológicas o alinhamento dessas feições. O padrão de drenagem do tipo treliça contrasta com o subdendrítico regional, indicando a importante estruturação tectônica.

Silva e Ferrari (1997) reconheceram um importante controle tectônico para a compartimentação geomorfológica na área, relacionado à marcante retilinearidade dos limites das unidades de relevo, sobretudo nas direções ENE-WSW, coincidentes com as principais falhas terciárias.

\section{METODOLOGIA}

\section{Análise morfoestratigráfica}

O reconhecimento estratigráfico é de suma importância para a ordenação cronológica dos mecanismos neotectônicos, individualizando cada evento para possível correlação com dados apresentados na literatura.

Uma característica particular dos depósitos cenozoicos está no fato de não se encontrarem restritos a bacias sedimentares, mas distribuírem-se relacionados geneticamente com as feições geomorfológicas. $\mathrm{O}$ entendimento das relações entre depósitos sedimentares cenozoicos e formas do relevo torna-se, assim, de grande importância para o estudo do registro sedimentar cenozoico.

Meis e Moura (1984) propuseram que o conceito de morfoestratigrafia deve ser restringido a condições em que seja possível detectar, com base na lito- ou aloestratigrafia, uma relação genética direta entre o depósito e a forma topográfica. Definiram, então, unidades morfoestratigráficas como corpos sedimentares onde é possível detectar uma relação entre a gênese da forma e o depósito. A concepção de unidade morfoestratigráfica proposta enfatiza a necessidade do reconhecimento de superfícies deposicionais (Mello, 1997), tornando-se fundamental a realização de análises estratigráficas detalhadas.

Segundo Suguio (1999), depois de diagnosticadas as relações de antiguidade entre as superfícies deposicionais, as idades relativas dos depósitos sedimentares componentes ficam estabelecidas. Utilizando esta metodologia, torna-se possível a sistematização no tempo e espaço das relações existentes entre as superfícies deposicionais que ocorrem em determinada área, estabelecendo, assim, a história de sua evolução geomorfológica.

Neste estudo, as unidades morfoestratigráficas foram individualizadas segundo as suas diferentes posições topográficas e características dos depósitos geneticamente relacionados. Buscou-se correlacioná-las a unidades descritas em outras áreas no sudeste do Brasil (Moura e Meis, 1986; Mello et al., 1995; Mello, 1997; Peixoto, 2002). As idades dessas superfícies foram determinadas a partir das análises aloestratigráfias conduzidas por estes autores.

\section{Análise estrutural}

Esta etapa do trabalho iniciou-se com a coleta sistemática de dados estruturais, afetando sedimentos cenozoicos e as rochas do embasamento, quando estas se mostravam profundamente alteradas pela ação do intemperismo.

Procurou-se distinguir, a partir dos critérios morfoestratigráficos mencionados anteriormente, as unidades cenozoicas afetadas por essas estruturas, para o estabelecimento da cronologia relativa dos eventos neotectônicos ocorridos na região.

No caso de medidas em falhas, para que pudessem indicar a movimentação ocorrida, foi feito o reconhecimento de estrias direcionais contidas nos planos, elementos deslocados e estruturas de arrasto. Com a finalidade de obter um maior controle na cronologia dos eventos, procurou-se perceber a superposição de estrias em um mesmo plano de falha.

As falhas foram classificadas quanto ao tipo (normal, sinistral ou dextral), orientação e unidade estratigráfica afetada, determinando conjuntos de estruturas que poderiam ter sido criadas ou reativadas por um dado campo de 
paleotensão (distensional, compressional ou transcorrente). Nesta etapa, as estruturas geradas por paleotensões direcionais foram agrupadas com base no modelo de Riedel.

De modo a definir os campos de paleotensões geradores das estruturas rúpteis investigadas, os conjuntos de pares de falhas e estrias (dados pareados) foram analisados com o uso do programa TENSOR (Delvaux, 1993), que se fundamenta no método dos diedros retos proposto por Angelier e Mechler (1977, apud Angelier, 1994).

\section{RESULTADOS}

\section{Unidades morfoestratigráficas}

$\mathrm{Na}$ área de estudo, puderam ser caracterizadas quatro unidades morfoestratigráficas (Figura 2), constituindo feições geomorfológicas geneticamente associadas a pacotes sedimentares, segundo conceito apresentado por Meis e Moura (1984).

a. Superfície Aplainada - esta unidade corresponde a extensas superfícies sub-horizontais, preservadas como divisores de águas amplos e suaves. Em relação aos depósitos sedimentares associados, verifica-se a presença de uma cobertura areno-argilosa castanho-amarelada a avermelhada, litologicamente bastante homogênea, que ocorre diretamente em discordância erosiva sobre o embasamento alterado, assinalada pela presença de pavimento de seixos e blocos quartzosos, com a presença ocasional de litoclastos. Mello (1997) propôs uma idade pliocênica para esta sedi- mentação na região do vale do Rio Doce (MG), baseado em estudos de geocronologia do intemperismo realizados por Vasconcelos et al. (1992). Recentemente, estudos palinológicos realizados por Antonioli et al. (2005) em depósitos correlatos encontrados na depressão rio Pomba-Muriaé (MG) apontaram idade Mioceno/Plioceno.

b. Ombreira/Terraço de Cascalho reafeiçoado como Interflúvios - corresponde a interflúvios largos e suaves localizados no interior de vales fluviais, levemente inclinados rumo à drenagem e eventualmente servindo como divisores de pequenos tributários. Quando estas feições apresentam-se mais amplas, podem assemelhar-se a formas reafeiçoadas de terraços, exibindo topos achatados com contornos ligeiramente arredondados. Esta unidade encontra-se em posição topográfica acima da unidade Rampa/ Terraço de Acumulação. A estas feições associam-se materiais areno-argilosos, amarelados, com muitos grânulos dispersos e sem estruturas sedimentares presentes, exceto discretos alinhamentos de grânulos mal definidos. Na base destes depósitos ocorre, frequentemente, uma camada de cascalhos sustentados por clastos arredondados, denotando transporte fluvial. Estes depósitos ocorrem em discordância erosiva sobre o embasamento cristalino alterado. Mello (1997) afirma que este padrão sedimentar, em conjunto com a configuração morfológica exibida, sugere que a gênese desta feição seja decorrente do remodelamento parcial a total de uma superfície de deposição aluvial, admitindo uma idade pleistocênica. Peixoto (2002) apresenta a mesma idade para depósitos correlatos no médio vale do rio Paraíba do Sul (SP/RJ).

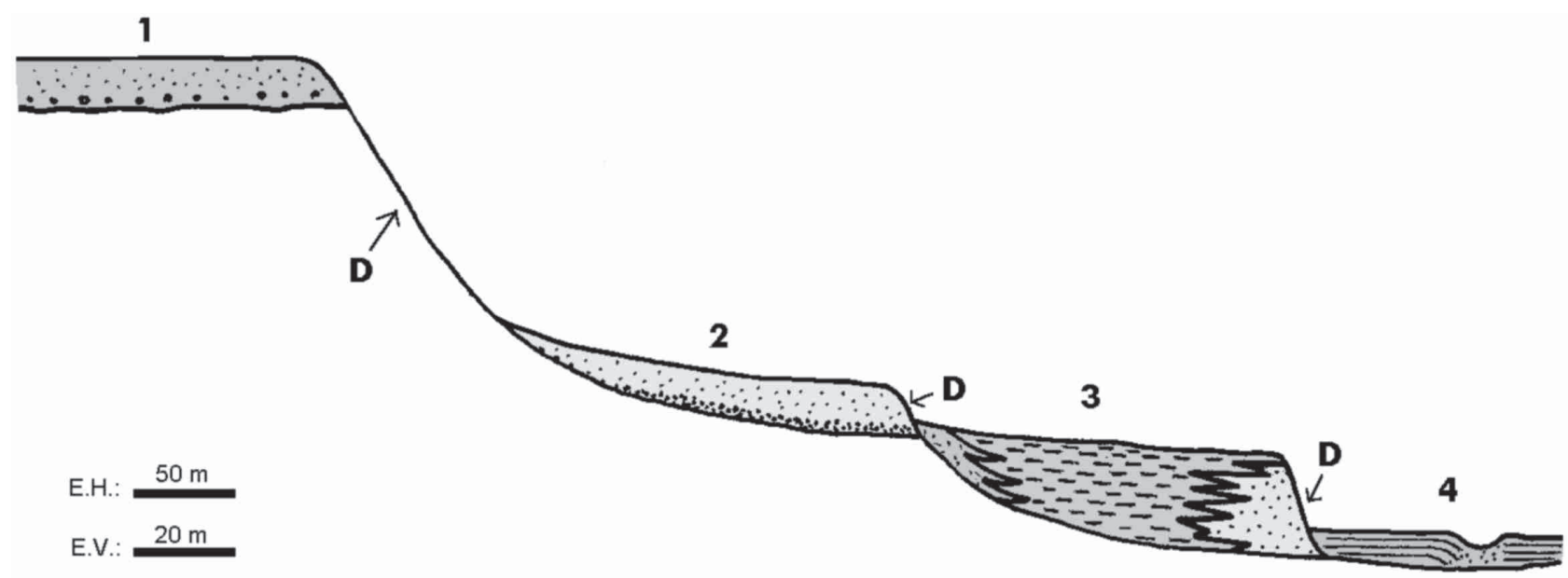

Figura 2. Relações morfoestratigráficas descritas por Mello (1997) na região do médio vale do rio Doce (MG), e também identificadas na área do presente estudo: 1. Superfície aplainada; 2. Ombreira/terraço de cascalho reafeiçoado como interflúvios; 3. Rampa/terraço de acumulação; 4. Terraço baixo/Planície de inundação; D. Discordâncias erosivas. Vide texto para detalhes sobre o preenchimento sedimentar. 
c. Rampa/Terraço de Acumulação - esta unidade associa-se a feições de rampas e terraços fluviais de acumulação. As rampas constituem formas de fundo de cabeceiras de drenagem e de vales de pequena ordem hierárquica, com geometria plana a côncava, suavemente inclinadas para jusante, e que resultam do entulhamento destes pequenos vales. $\mathrm{O}$ terraço de acumulação constitui uma superfície marcante de entulhamento dos vales fluviais, em continuidade às rampas, apresentando-se por toda a área de estudo, principalmente nos vales fluviais principais. Os depósitos sedimentares descritos nas rampas são compostos por areias grossas, argilosas, castanho-avermelhadas, com muitos grânulos dispersos, sem estruturas sedimentares ou incipientemente estratificadas. Estes materiais representam depósitos de natureza coluvial a colúvio-aluvial. A principal característica dos depósitos do terraço de acumulação é a intercalação de camadas tabulares de areias grossas e siltes argilosos, de coloração avermelhada a amarelada. Com base na correlação com unidades estratigráficas descritas por Moura e Mello (1991) e Mello (1992), no médio vale do rio Paraíba do Sul (SP/RJ), e Mello (1997), no médio vale do rio Doce (MG), pode ser atribuída idade holocênica para estes depósitos.

d. Terraço Baixo/Planície de Inundação - corresponde a feições planas em vales fluviais, poucos metros acima do nível da drenagem, acompanhando os cursos fluviais. Seus depósitos são caracterizados pela intercalação de areias finas a grossas, com estratificações cruzadas, e siltes argilosos, castanhos a acinzentados, com boa preservação de restos vegetais. Os sedimentos desta feição são de idade holocênica.

\section{Padrões de fraturamento neotectônico}

Os dados estruturais analisados consistem em um total de 94 planos de falhas com estrias, medidos em depósitos cenozoicos e no embasamento alterado, ao longo de 14 locais de coleta - JF01, JF04, JF05, JF06, JF08, MB02, MB03, MB04, MB05, PS01, MP01, MP03, MP04 e MP05. Os códigos dados aos afloramentos investigados referem-se à abreviatura dos nomes das cartas topográficas do IBGE e a ordem em que foram estudados.

\section{Ponto JF01}

Este afloramento corresponde a um corte de estrada em relevo de colinas, localizado no $\mathrm{km} 780$ da BR-040, no trecho ao largo da cidade de Juiz de Fora/MG (UTM, zona 23S: 0660737/7598212, datum Córrego Alegre, MG). Caracteriza-se pela presença de uma cobertura argilo-arenosa, castanho-amarelada, com nível de cascalhos na base, em inconformidade com o embasamento alterado. Esta cobertura foi correlacionada à unidade morfoestratigráfica Superfície Aplainada.

Foram observadas, ao longo do afloramento, estruturas que deslocam o contato cobertura cenozoica/embasamento (Figura 3A). Correspondem a planos de falha que se apresentam estriados (Figura 3B), inclusive com a presença de planos com duas estrias superpostas. Algumas dessas falhas possuem orientação e mergulho próximos aos da foliação metamórfica do embasamento, sugerindo o aproveitamento de zonas de fraqueza estrutural pretéritas.

Foram identificados dois conjuntos de falha: o primeiro conjunto é formado por falhas sinistrais normais de orientação WNW-ESE e ENE-WSW, falha dextral normal NNE-SSW, e falhas normais de direção NE-SW associadas à compressão NE-SW e distensão NW-SE (Figura 3D); o segundo conjunto, associado à compressão NNW-SSE e distensão ENE-WSW, é representado por falhas transcorrentes dextrais de direção variando de WNW-ESE a ENE-WSW e NW-SE, e falhas normais NNW-SSE e NW-SE (Figura 3E). As falhas relacionadas ao segundo conjunto apresentam-se conjugadas, exibindo padrão romboédrico típico de cisalhamento rúptil (Figura 3C).

\section{Ponto MBO4}

Este ponto está localizado na estrada para Monte Verde (MG-353), antes de cruzar o rio São Mateus, a aproximadamente $5 \mathrm{~km}$ da BR-040, no município de Juiz de Fora/ MG (UTM, zona 23S: 0664279/7583351, datum Córrego Alegre, MG).

O embasamento mostra-se muito alterado, com material argiloso de coloração rosada. Truncando o embasamento, ocorrem sedimentos areno-argilosos, castanho-amarelados, com nível de cascalhos na base (Figura 4A), relacionados à unidade morfoestratigráfica Superfície Aplainada.

Foram medidas diversas falhas com características diferentes, afetando a cobertura cenozoica. Estas estruturas foram divididas em dois grupos: o primeiro grupo é formado por falhas dextrais normais de direção NNW-SSE a NW-SE, associadas a uma distensão NW-SE e compressão NE-SW (Figura 4B); um segundo grupo é composto por falhas normais com orientação predominante NW-SE, com planos NNW-SSE e WNW-ESE, geradas sob um campo de esforços distensivos NE-SW e compressivos NW-SE (Figura 4C).

Também neste ponto, foi possível observar a superposição de estrias em dois planos de falha, documentando que a movimentação associada às falhas do segundo conjunto, com estrias mais pronunciadas, foi posterior à movimentação relacionada às falhas do primeiro conjunto. 


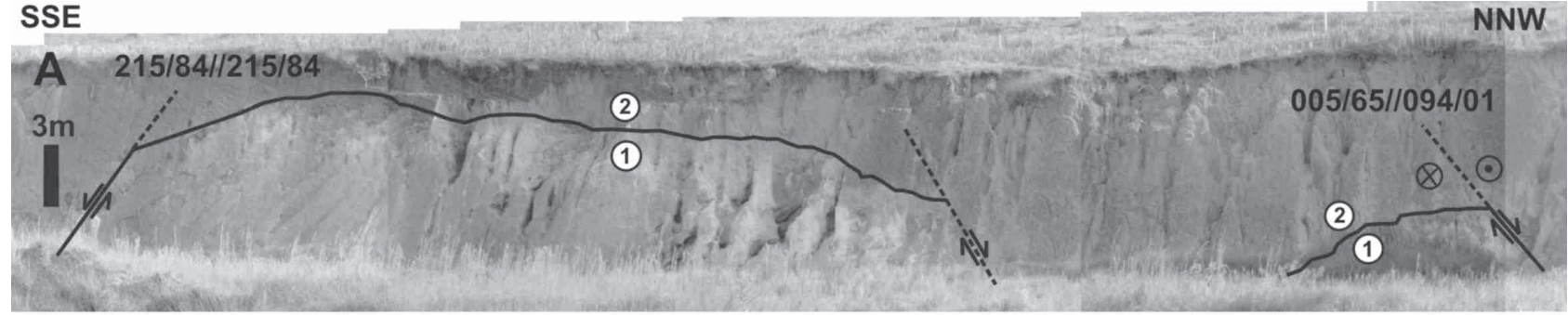

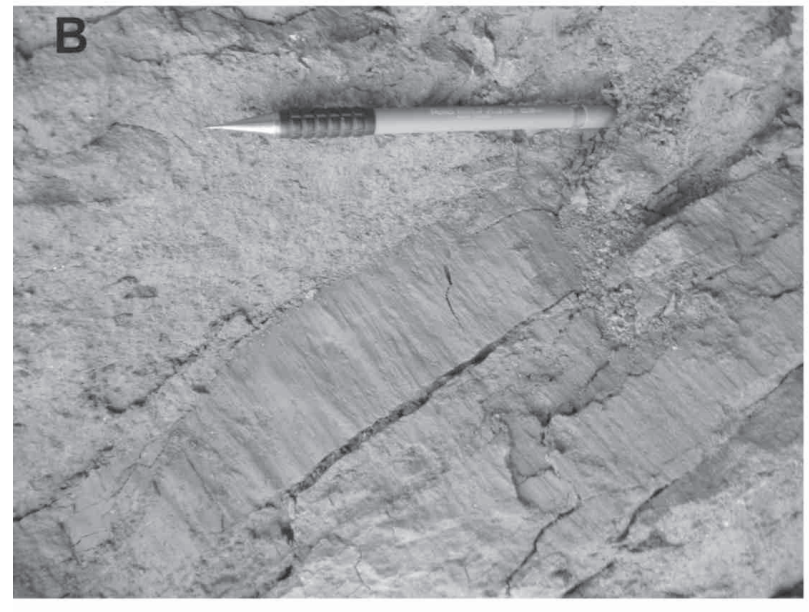

D

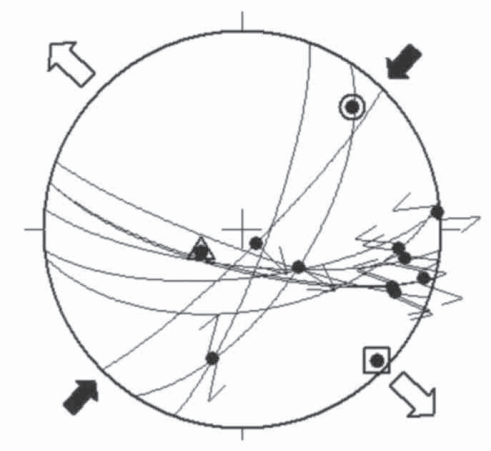

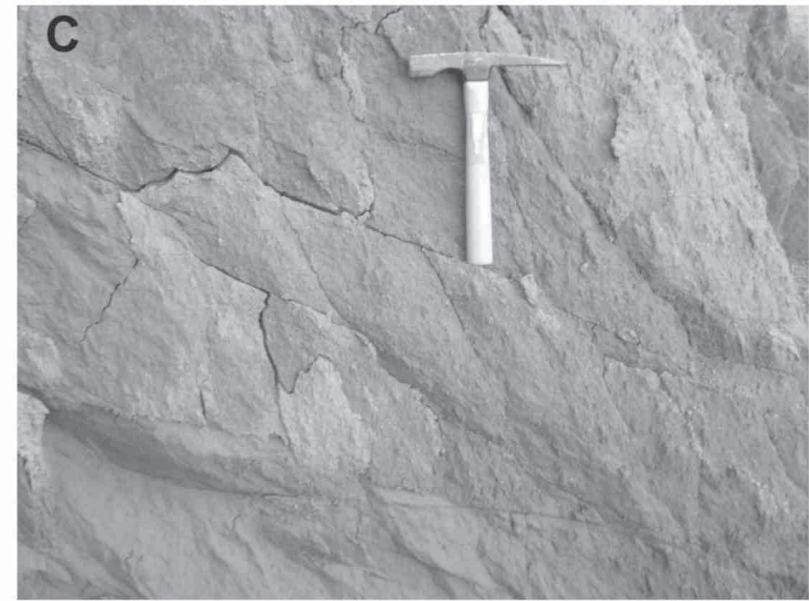

E

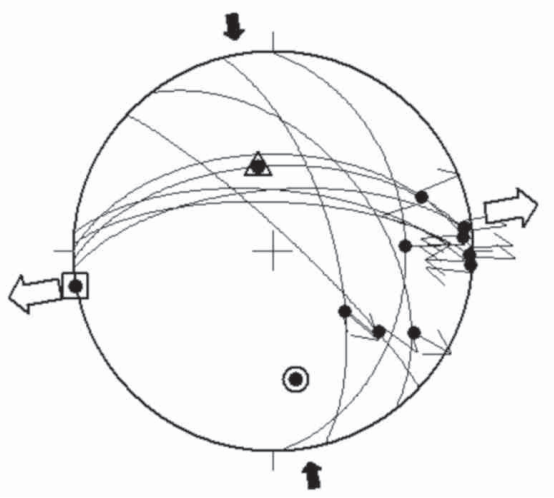

Figura 3. A. Interpretação, com base em fotomosaico, da distribuição das unidades geológicas identificadas no ponto JF01. Destacam-se os planos de falha dextral WNW-ESE e normal NW-SE que afetam o embasamento alterado (1) e a cobertura neogênica (2). Linhas tracejadas: planos de falha inferidos. B. Fotografia de detalhe de plano de falha oblíqua, normal e sinistral, medido no embasamento alterado. C. Planos de falha conjugados, em padrão romboédrico, medidos na cobertura neogênica. D. Projeção estereográfica (Schmidt-Lambert, hemisfério inferior) de falhas normais NE-SW, sinistrais normais de direção WNW-ESE a ENE-WSW, e dextral normal NNE-SSW, associadas à compressão NE-SW e distensão NW-SE. E. Projeção estereográfica (Schmidt-Lambert, hemisfério inferior) de falhas dextrais normais de direção WNW-ESE a ENE-WSW e NW-SE, e falhas normais NNW-SSE e NW-SE, associadas à compressão NNW-SSE e distensão ENE-WSW. Simbologia: círculo $=\sigma 1$; triângulo $=\sigma 2$; quadrado $=\sigma 3$; setas grandes cheias $=$ eixos compressivos horizontais; setas grandes vazias $=$ eixos distensivos horizontais. 

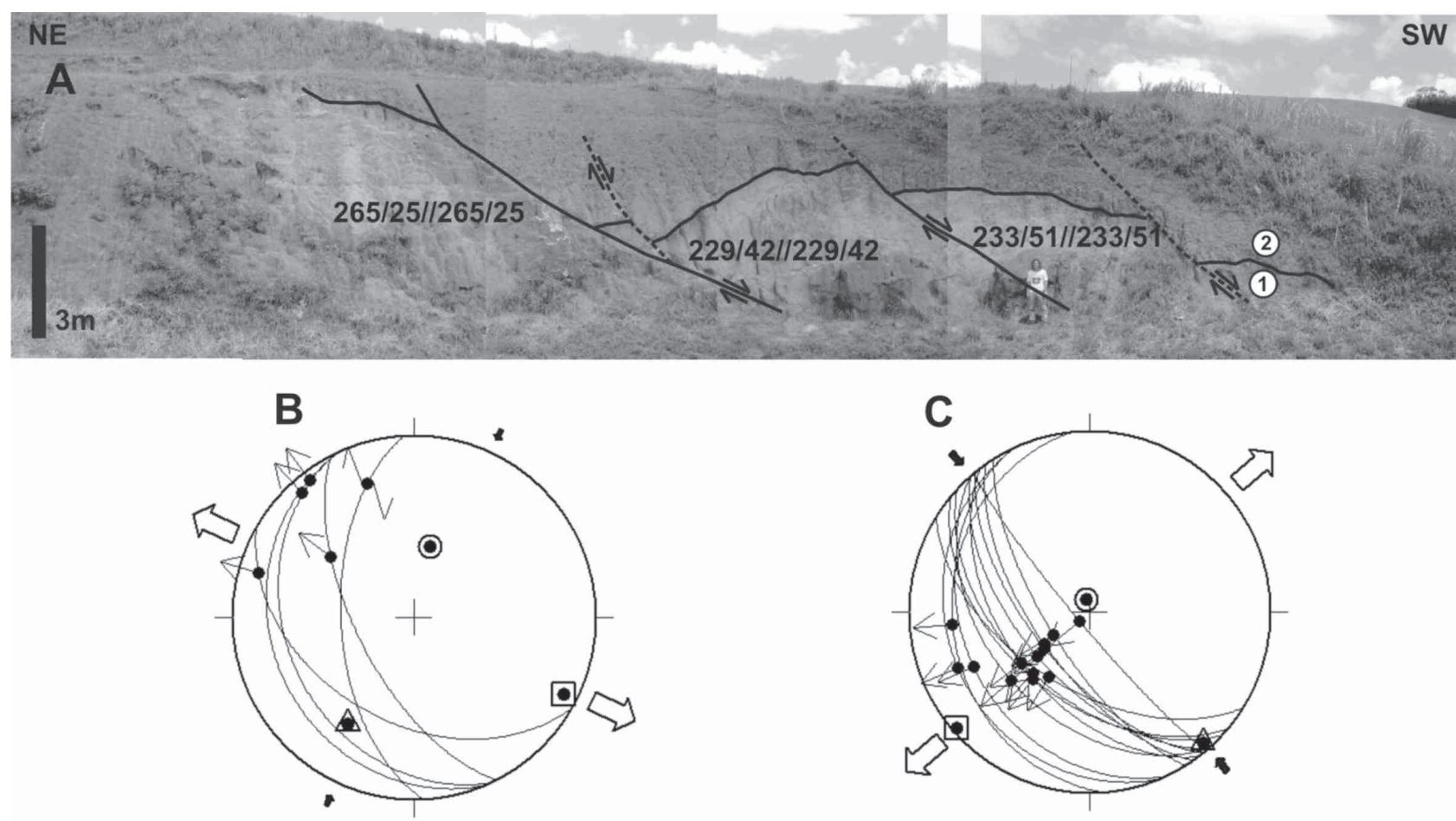

Figura 4. A. Interpretação, com base em fotomosaico, da distribuição das unidades geológicas identificadas no ponto MB04. Destacam-se os planos de falhas normais NNW-SSE e NW-SE que afetam o embasamento alterado (1) e a cobertura neogênica (2). Linhas tracejadas: planos de falha inferidos. B. Projeção estereográfica (Schmidt-Lambert, hemisfério inferior) de falhas dextrais normais NNW-SSE a NW-SE, relacionadas a uma distensão NW-SE e compressão NE-SW. C. Projeção estereográfica (Schmidt-Lambert, hemisfério inferior) de falhas normais de direção NW-SE e NNW-SSE, relacionadas a uma distensão NE-SW e compressão NW-SE. Simbologia: círculo $=\sigma 1$; triângulo $=\sigma 2$; quadrado $=\sigma 3$; setas grandes cheias $=$ eixos compressivos horizontais; setas grandes vazias $=$ eixos distensivos horizontais.

\section{Ponto PSO1}

Neste ponto, situado na BR-393, na margem esquerda do rio Paraíba do Sul, próximo ao Engenho Vieira Côrtes, entre Andrade Pinto e Paraíba do Sul (UTM, zona 23S: 0667519/7543525, datum Córrego Alegre, MG), foram reconhecidos sedimentos alúvio-coluviais, relacionados à unidade morfoestratigráfica Rampa/Terraço de Acumulação, sobre rochas do embasamento com diferentes graus de alteração, eventualmente mantendo a foliação metamórfica.

Foram identificadas falhas que deslocam o contato entre o embasamento e o pacote sedimentar (Figura 5A). Devido à composição arenosa destes depósitos, poucos planos puderam ser medidos com segurança, entre os quais foram medidos cinco pares falha/estria, com um plano apresentando estrias superpostas.
Os planos de falha medidos foram separados em dois conjuntos: o primeiro é formado por falhas dextrais com orientação NE-SW, originadas a partir de esforços distensivos NE-SW e esforços compressivos NW-SE (Figura 5B); o segundo conjunto é composto por falhas normais de direção NE-SW, originadas a partir de esforços distensivos NW-SE (Figura 5C). A partir da análise da relação entre as estrias superpostas em um mesmo plano de falha, admite-se que a movimentação relacionada ao segundo conjunto é mais recente.

\section{Ponto MP04}

Neste afloramento, descrito na RJ-125, a $4 \mathrm{~km}$ de Avelar, em direção a Andrade Pinto, logo após cruzar o rio Ubá (UTM, zona 23S: 0664822/7533105, datum Cór- 

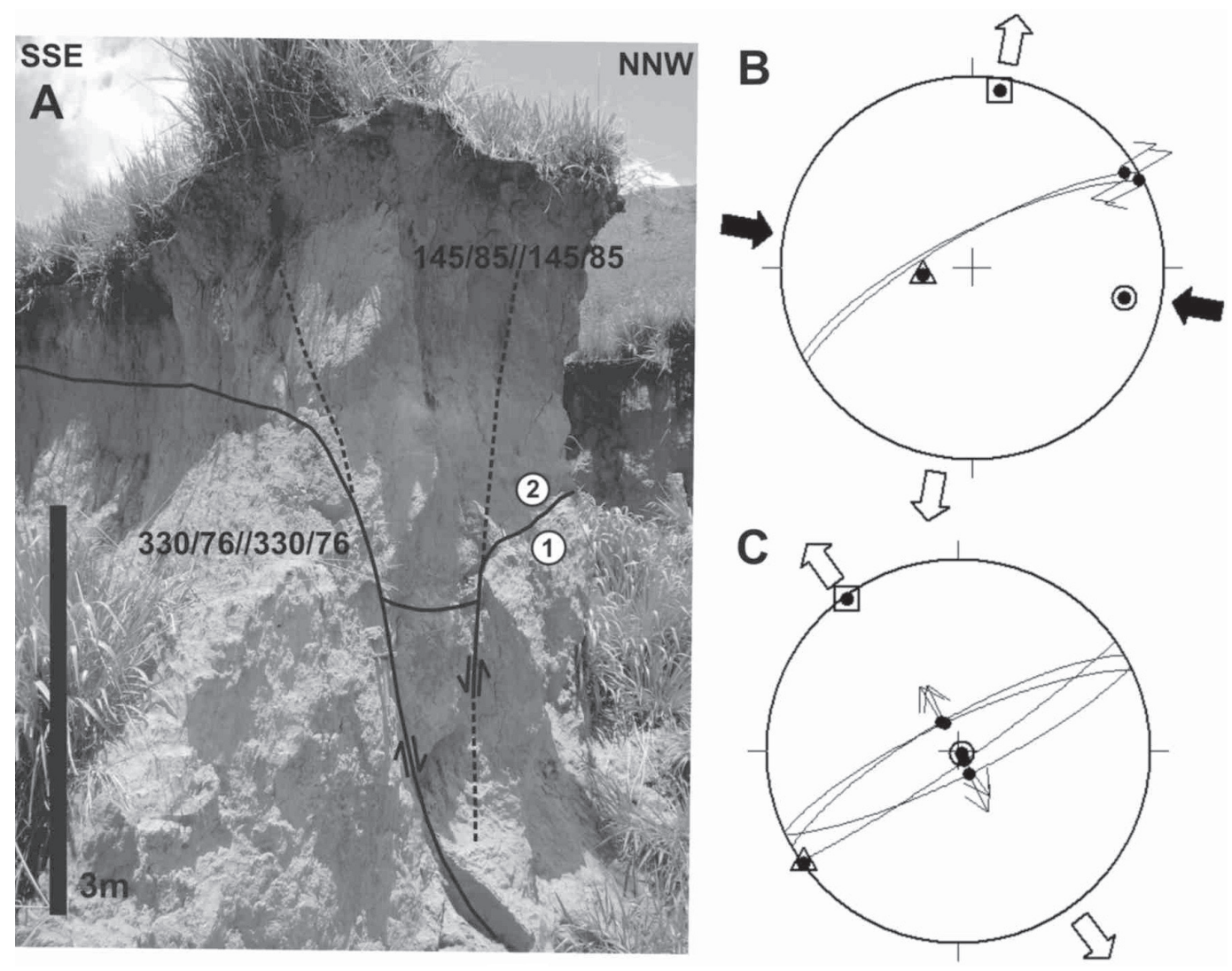

Figura 5. A. Interpretação, com base em fotomosaico, da distribuição das unidades geológicas identificadas no ponto PSO1, situado na Zona de Cisalhamento do Rio Paraíba do Sul. Destacam-se os planos de falhas normais NE-SW que afetam o embasamento alterado (1) e depósitos alúvio-coluviais holocênicos (2). Linhas tracejadas: planos de falha inferidos. B. Projeção estereográfica (Schmidt-Lambert, hemisfério inferior) de falhas dextrais normais de direção NE-SW, relacionadas a uma compressão WNW-ESE e distensão NNE-SSW. C. Projeção estereográfica (Schmidt-Lambert, hemisfério inferior) de falhas normais de direção NE-SW, relacionadas a uma distensão NW-SE. Simbologia: círculo $=\sigma 1$; triângulo $=\sigma 2 ;$ quadrado $=\sigma 3$; setas grandes cheias $=$ eixos compressivos horizontais; setas grandes vazias = eixos distensivos horizontais.

rego Alegre, MG), foram identificados depósitos da $\mathrm{Su}$ perfície Aplainada em inconformidade com o embasamento alterado, afetados por dois conjuntos de falhas (Figuras 6A e 6B). O primeiro é formado por planos dextrais com orientação NE-SW, gerados por esforços distensivos NE-SW e compressivos NW-SE (Figura 6C). O segundo conjunto inclui um número maior de falhas, de caráter normal e orientação NE-SW e ENE-WSW, relacionadas a esforços distensivos NW-SE (Figura 6D). Planos de falha apresentando estrias superpostas indicam terem sido reativados por estes dois campos de esforços tectônicos, podendo ser caracterizado o segundo conjunto como o mais recente.

\section{Fases Tectônicas}

A partir da análise dos campos de tensão geradores das estruturas rúpteis, aliada às relações cronológicas reconhecidas, foram individualizadas três fases tectônicas, passíveis de correlação a regimes neotectônicos descritos em outras áreas do sudeste do Brasil (Figura 7). Estas fases serão apresentadas a seguir, relacionando-se o pa- 

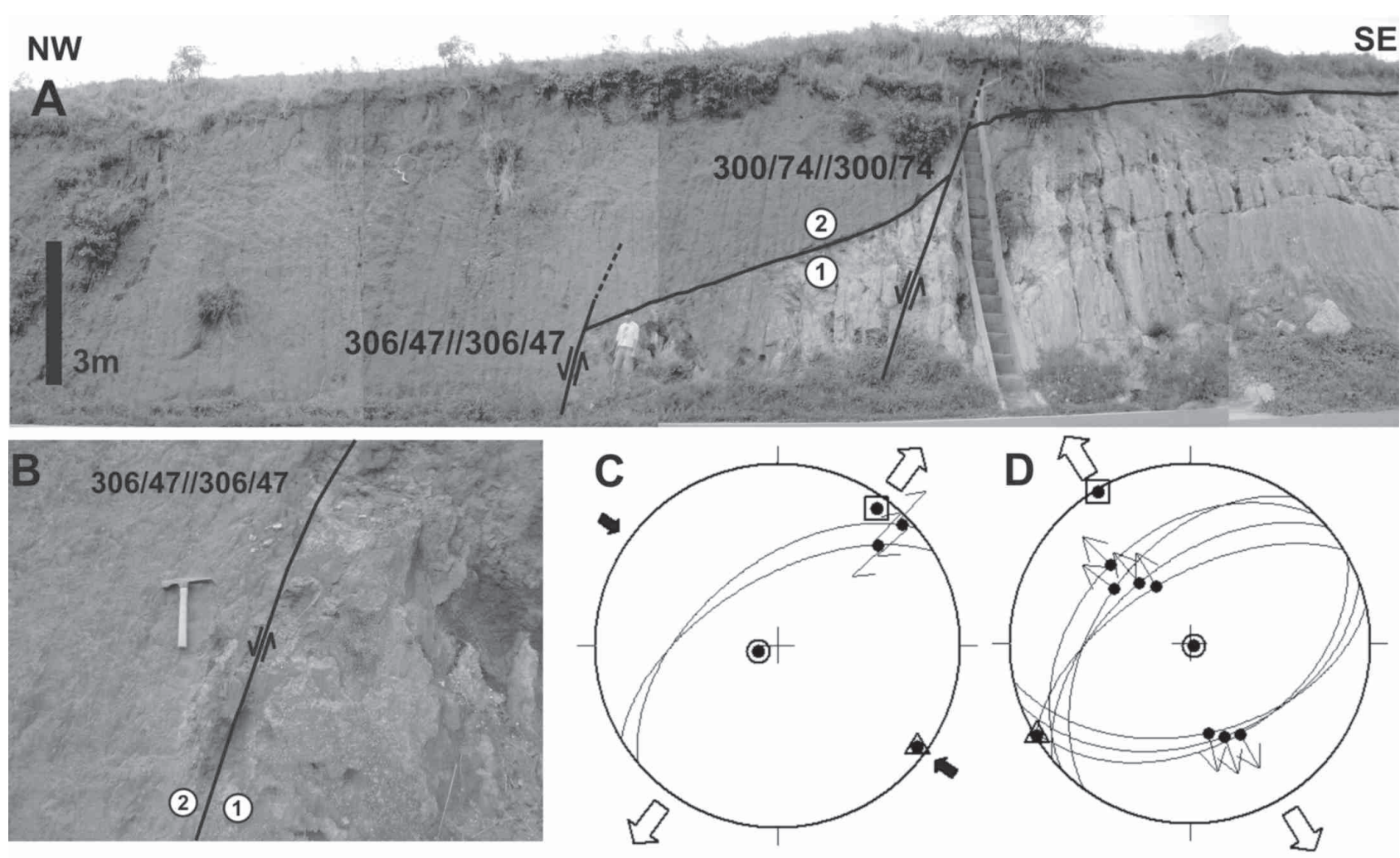

Figura 6. A. Interpretação, com base em fotomosaico, da distribuição das unidades geológicas identificadas no ponto MP04, situado na Zona de Cisalhamento do Rio Paraíba do Sul. Destacam-se os planos de falhas normais NE-SW que afetam o embasamento alterado (1) e a cobertura neogênica (2). Linhas tracejadas: planos de falha inferidos. B. Detalhe de plano de falha medido no contato entre o embasamento alterado e a cobertura cenozóica (plano à esquerda no fotomosaico). C. Projeção estereográfica (Schmidt-Lambert, hemisfério inferior) de falhas dextrais normais de direção NE-SW, relacionadas a uma distensão NE-SW e compressão NW-SE. D. Projeção estereográfica (Schmidt-Lambert, hemisfério inferior) de falhas normais de direção NE-SW a ENE-WSW, relacionadas a uma distensão NW-SE. Simbologia: círculo $=\sigma 1$; triângulo $=\sigma 2$; quadrado $=\sigma 3$; setas grandes cheias $=$ eixos compressivos horizontais; setas grandes vazias $=$ eixos distensivos horizontais.

drão de fraturamento produzido e as unidades estratigráficas afetadas.

\section{Transcorrência sinistral E-W (TS E-W)}

As estruturas relacionadas a esta fase tectônica são, em sua maioria, falhas normais NE-SW e normais dextrais NNE-SSW, apresentando, também, falhas normais sinistrais NE-SW, ENE-WSW e WNW-ESE, e falhas normais dextrais NW-SE e NNW-SSE. Estas estruturas foram medidas em rochas do embasamento alteradas, não tendo sido observadas afetando os depósitos cenozoicos. Com base nos diagramas de paleotensão, foram geradas a partir de esforços de distensão NW-SE e compressão NE-SW.

Este evento é correlacionável à primeira fase de deformação tectônica proposta por Riccomini (1989), Salvador e Riccomini (1995) e Riccomini, Sant'Anna e Ferrari (2004) para o RCSB. Segundo Riccomini, Sant'Anna e Ferrari (2004), esta fase tectônica data do Mioceno. Também foi identificada por Mello (1997) e Sarges (2002), na região do médio vale do rio Doce (MG), que a posicionaram no Neógeno.

Esta fase tectônica encontra-se bem documentada nos pontos JF01, JF04, JF06, MB04 e MB05, como se obser- 


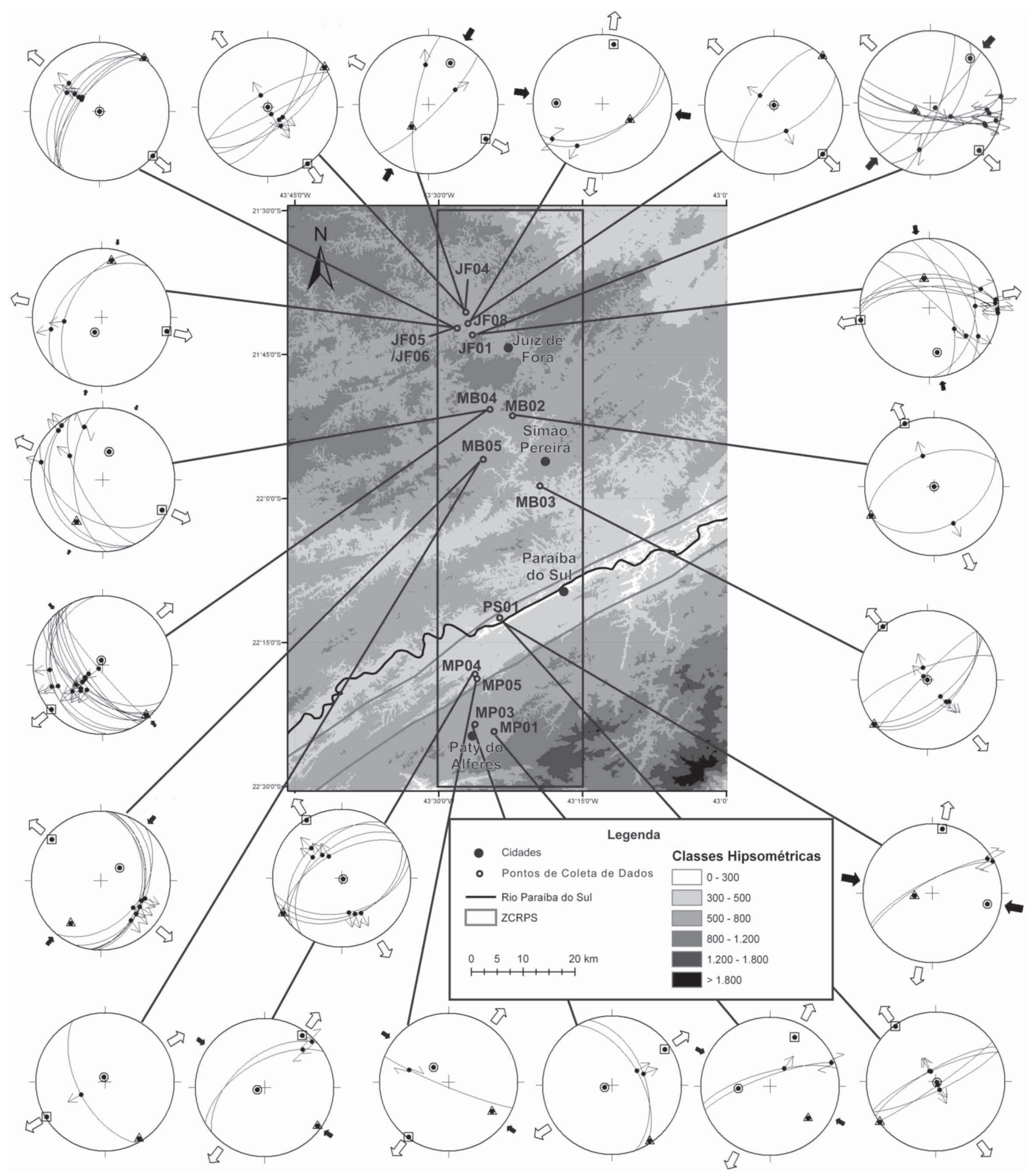

Figura 7. Distribuição sobre mapa hipsométrico dos pontos de coleta de dados estruturais relacionados às fases tectônicas de transcorrência sinistral E-W, transcorrência dextral E-W e distensão NW-SE. 
va no mapa de distribuição das estruturas associadas esta fase tectônica.

\section{Transcorrência dextral E-W (TD E-W)}

As estruturas relacionadas a esta fase tectônica são, em sua maioria, falhas normais NW-SE e normais dextrais NE-SW e NW-SE, apresentando, também, falhas normais NNW-SSE e WNW-ESE, e normais dextrais E-W, ENE-WSW e WNW-ESE. As falhas com orientação WNW-ESE a ENE-WSW e NE-SW apresentam um forte caráter transcorrente, enquanto as estruturas NW-SE apresentam um comportamento mais distensivo. Estas estruturas afetam as coberturas cenozoicas associadas às unidades morfoestratigráficas correlatas à Superfície Aplainada e à Ombreira/Terraço de Cascalho Reafeiçoado como Interflúvio. Com base nos diagramas de paleotensão, foram geradas a partir de esforços de compressão NW-SE e distensão NE-SW.

De acordo com as relações estratigráficas observadas e, também, a partir da identificação de estrias superpostas em um mesmo plano de falha, admite-se que as estruturas relacionadas à transcorrência dextral E-W sejam mais recentes do que aquelas geradas no evento de transcorrência sinistral E-W.

Este evento é correlacionável à segunda fase de deformação tectônica proposta por Riccomini (1989), Salvador e Riccomini (1995) e Riccomini, Sant'Anna e Ferrari (2004) para o RCSB, a que estes autores atribuíram uma idade pleistocênica. Também foi identificada por Mello (1997) e Sarges (2002), na região do médio vale do rio Doce (MG), que a posicionaram no Pleistoceno tardio a Holoceno inicial; e por Ferrari (2001), no Gráben da Guanabara, que posicionou esta fase no Pleistoceno.

Através da análise da distribuição das estruturas relativas a esta fase tectônica, descritas nos pontos JF01, JF08, MB04, MB05, PS01, MP01, MP03, MP04 e MP05, nota-se que estão bem representadas em toda área de estudo. Os pontos onde foram identificadas estas estruturas posicionam-se próximos a feixes de orientação NW-SE, particularmente nos compartimentos a norte da ZCRPS. Nos compartimentos Paraíba do Sul e Paty do Alferes, as estruturas relativas a esta fase tectônica sugerem a reativação de estruturas NE-SW pretéritas.

\section{Distensão NW-SE (D NW-SE)}

As estruturas pertencentes a essa fase tectônica são falhas normais segundo a direção NE-SW, geradas por um campo de esforços distensivos de orientação NW-SE, que afetam desde o embasamento alterado até os sedimentos alúvio-coluviais holocênicos.
Com base nas relações estratigráficas e, também, a partir da identificação de estrias superpostas em um mesmo plano de falha, este evento foi considerado como o de idade mais recente. Existem diversos planos de falha que apresentam estrias de deslocamento com movimentação relacionada a esta fase superpostas tanto a estrias associadas ao evento de transcorrência sinistral E-W, quanto a estrias relativas ao regime de transcorrência dextral E-W.

Os pontos em que foram descritas estruturas pertencentes a esta fase tectônica ocorrem em toda a área de estudo, principalmente ao longo de feixes contínuos de orientação NE-SW, notavelmente ao longo da ZCRPS, indicando o caráter de reativação das estruturas pretéritas.

Este evento é correlacionável à terceira fase de deformação tectônica proposta por Riccomini (1989), Salvador e Riccomini (1995) e Riccomini, Sant'Anna e Ferrari (2004) para o RCSB, a que estes autores atribuíram uma idade holocênica. Também foi identificada por Mello (1997) e Sarges (2002), na região do médio vale do rio Doce (MG), que também a posicionaram no Holoceno.

\section{CONCLUSÕES}

Os dados obtidos neste estudo apontam para a atuação de fases neotectônicas sucessivas na evolução cenozoica da região Sudeste do Brasil, concordando com diversos trabalhos anteriores realizados nesta região (Figura 8). Entre estas fases, destaca-se a maior representatividade do evento neotectônico de transcorrência dextral E-W, de idade Pleistoceno-Holoceno.

As estruturas de deformação neotectônica apresentam, em grande parte, forte relação com as descontinuidades pré-cambrianas, mostrando a reativação da Zona de Cisalhamento do Rio Paraíba do Sul durante o Cenozoico. Corrobora-se a ideia de uma tectônica ressurgente, conforme sugerido por Hasui (1990), no sentido de que as estruturas neotectônicas sofreram o controle efetivo das anisotropias preexistentes:

1. em resposta aos esforços de compressão NE-SW e distensão NW-SE relacionados ao evento de transcorrência sinistral E-W, miocênico, as faixas de cisalhamento pré-cambrianas, orientadas segundo a direção NE-SW, foram reativadas como falhas normais e normais sinistrais. Com base no modelo de Riedel, corresponderiam, respectivamente, a falhas T e R;

2. estas mesmas estruturas foram novamente reativadas, agora como falhas dextrais normais, sob os esforços de compressão NW-SE e distensão NE-SW relacionados à fase de transcorrência dextral E-W, pleistocênica-holocênica. Corresponderiam, nesta situação, a falhas do tipo P, no modelo de Riedel; 


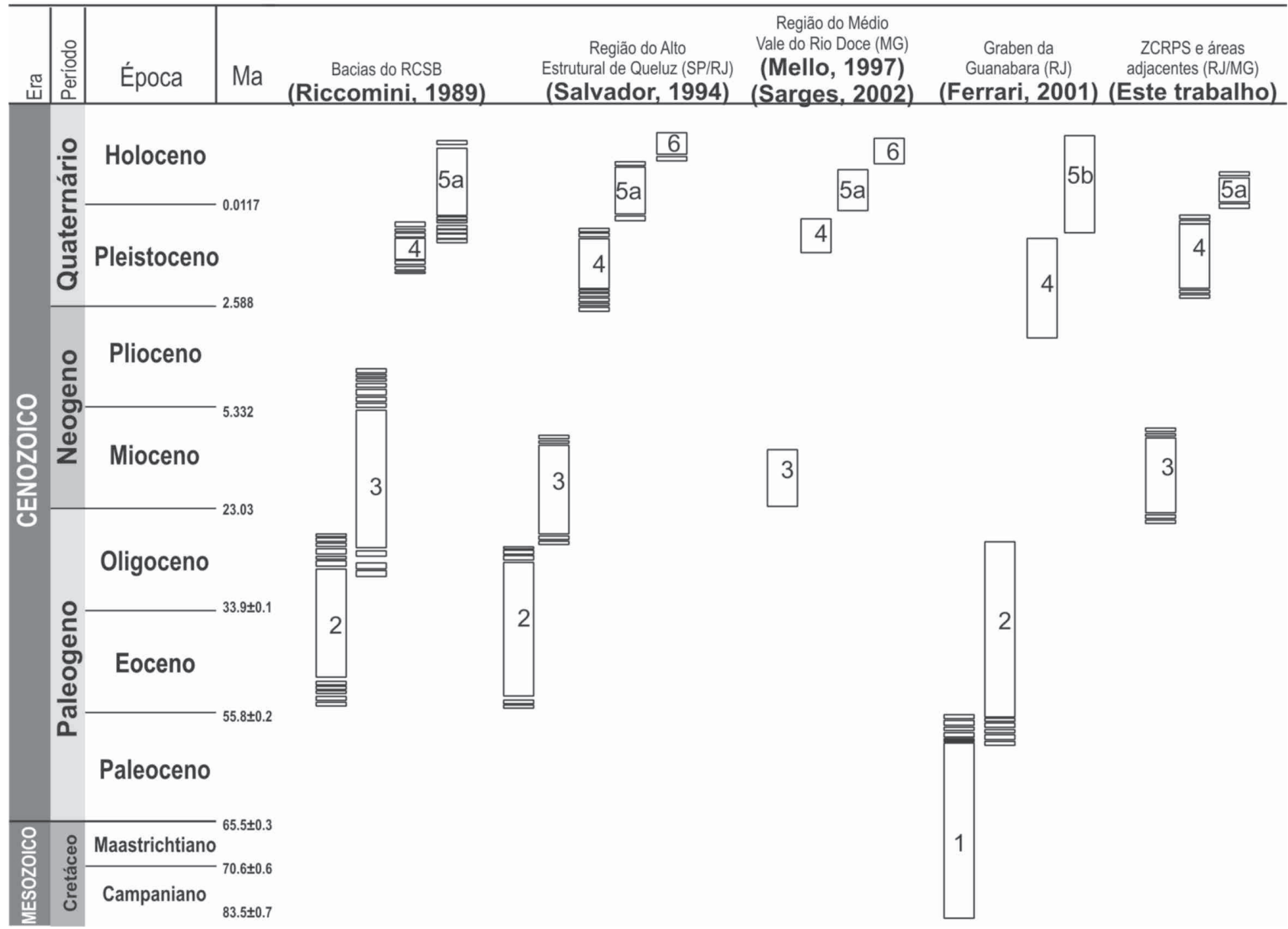

Figura 8. Quadro de fases tectônicas cenozóicas no Sudeste do Brasil segundo diferentes autores e regiões, incluindo as fases propostas no presente trabalho. Modificado de Mello e Ferrari (2003). 1. Transcorrência sinistral E-W; 2. Distensão NW(NNW)-SE(SSE); 3. Transcorrência sinistral E-W; 4. Transcorrência dextral E-W; 5a. Distensão NW(WNW)-SE(ESE); 5b. Distensão E-W; 6. Compressão E-W.

3. o evento neotectônico mais recente, associado a um campo de esforços distensivo NW-SE, holocênico, reativou as estruturas NE-SW como falhas normais.

As estruturas tectônicas associadas à fase de transcorrência dextral E-W são as de maior ocorrência dentro da área de estudo, principalmente as falhas de caráter normal NW-SE, que podem representar a reativação de estruturas pretéritas com esta orientação, mas também podem ter sido neoformadas.

Considera-se que os novos dados aqui apresentados, integrados àqueles descritos em estudos efetuados em áreas vizinhas, podem contribuir para o refinamento dos modelos existentes, em particular pela avaliação dos da- dos neotectônicos em uma mais ampla e contínua extensão territorial.

\section{AGRADECIMENTOS}

Ao CNPq e ao Programa de Pós-graduação em Geologia (IGEO-UFRJ), pelo apoio financeiro para o desenvolvimento deste estudo. Aos professores Francisco Hilário Rego Bezerra (UFRN), Telma Mendes da Silva (UFRJ) e Henrique Dayan (UFRJ), pelas observações oferecidas na avaliação da dissertação de Mestrado que fundamentou o presente artigo. E, por fim, aos revisores Claudio Riccomini (USP) e Peter Hackspacher (UNESP), por seus comentários, correções e sugestões. 


\section{REFERÊNCIAS}

ALBUQUERQUE, A. P. B. Tectônica Deformadora Cenozóica na Bacia Sedimentar de Resende (Rift Continental do Sudeste do Brasil). 2004. Dissertação (Mestrado) - Departamento de Geologia, Instituto de Geociências, Universidade Federal do Rio de Janeiro, 2004.

ALMEIDA F. F. M.; HASUI Y.; CARNEIRO C. D. R. O lineamento de Além-Paraíba. Anais Academia Brasileira de Ciências, v. 48, p. 575, 1975.

ALMEIDA, F. F. M.; HASUI, Y.; BRITO NEVES, B. B.; FUCK, R. A. Províncias estruturais brasileiras. In: SIMPÓSIO DE GEOLOGIA DO NORDESTE, 8., 1977, Campina Grande. Atas... Campina Grande: SBG, 1977. p. 363-391.

ANGELIER, J. Fault slip analysis and paleostress reconstruction. In: HANCOCK, P. L. (Ed.). Continental Deformation. Oxford: Pergamon Press, 1994. p. 53-100.

ANGELIER, J.; MECHLER, P. Sur une méthode graphique de recherche des contraintes principales egalement utilisable en tectonique et en seismologie: la méthode des diédres droits. Bulletin de la Societe Geologique de France, v. 7, p. 1309-1318, 1977.

ANTONIOLI, L.; TUPINAMBÁ, M.; GRACIA, M. J.; DINO, R. Palinologia e idade de sedimentos neógenos (Mioceno superior/Plioceno) da depressão rio PombaMuriaé (MG). In: SIMPÓSIO DE GEOLOGIA DO SUDESTE, 9., 2005. Rio de Janeiro. Boletim de Resumos... Rio de Janeiro: SBG, 2005. p. 63.

CALDERANO, S. B.; LEMOS, A. L. Estudos geológicos no município de Paty do Alferes. In: WORKSHOP NACIONAL DE AGRICULTURA SUSTENTÁVEL EM REGIÕES TROPICAIS DE RELEVO ACIDENTADO, 3., 1998. Paty do Alferes. Boletim de pesquisa. Paty do Alferes: EMBRAPA-Solos, 1998. v. 9.

CAMPANHA, G. A. C. O Lineamento de Além-Paraíba na área de Três Rios (RJ). Revista Brasileira de Geociências, v. 11, n. 3, p. 159-171, 1981.

CORRÊA NETO, A. V.; DAYAN, H.; VALENÇA, J. G.; CABRAL, A. R. Geologia e estrutura da zona de cisalhamento do rio Paraíba do Sul e adjacências, no trecho entre Três Rios (RJ) e Sapucaia (RJ). In: SIMPÓSIO DE GEOLOGIA DO SUDESTE, 3., 1993. Rio de Janeiro. Atas... Rio de Janeiro: SBG, 1993. p. 194-200.
CORREA NETO, A. V.; DAYAN, H. Estudo dos indicadores cinemáticos na Zona de Cisalhamento do Rio Paraíba do Sul no trecho entre Três Rios (RJ) e Além Paraíba (MG). In: CONGRESSO BRASILEIRO DE GEOLOGIA, 39., 1996. Salvador. Anais... Salvador: SBG, 1996. p. 354-356.

DAYAN, H.; KELLER, J. V. A. A Zona de Cisalhamento do Rio Paraíba do Sul nas vizinhanças de Três Rios (RJ): uma análise da deformação dada por algumas feições estruturais. Revista Brasileira de Geociências, v. 19, n. 4, p. 494-506, 1990.

DELVAUX, D. The tensor program for paleostress reconstruction: examples from the East African and Baikal rift zones. Terra Nova, v. 5, n. 1, p. 216, 1993.

FERRARI, A. L. Evolução Tectônica do Graben da Guanabara. 2001. 412 f. Tese (Doutorado) - Instituto de Geociências, Universidade de São Paulo, São Paulo, 2001.

GATTO, L. C. S; RAMOS, V. L. S.; NUNES, B. T. A.; MAMEDE, L.; GÓES, M. H. B.; MAURO, C. A.; ALVARENGA, S. M.; FRANCO, E. M. S.; QUIRICO, A. F.; NEVES, L. B. Geomorfologia. In: Projeto Radambrasil, Brasília: DNPM, 1983. v. 32, p. 305-384.

GONTIJO-PASCUTTI, A. H. F.; BEZERRA, F. H. R.; TERRA, E.; ALMEIDA, J. C. H. Brittle Reactivation of Mylonitic Fabric and the Origin of the Cenozoic Rio Santana Graben, Southeastern Brazil. Journal of South American Earth Sciences, v. 29, p. 522-536, 2010.

HASUI, Y. Neotectônica e aspectos fundamentais da tectônica ressurgente no Brasil. In: WORKSHOP SOBRE NEOTECTÔNICA E SEDIMENTAÇÃO CENOZÓICA CONTINENTAL NO SUDESTE BRASILEIRO, 1., 1990, Belo Horizonte. Boletim... Belo Horizonte: SBG/ MG, 1990. p. 11-31.

HEILBRON, M.; PEDROSA-SOARES, A. C.; CAMPOS NETO, M. C.; SILVA, L. C.; TROUW, R. A. J.; JANASI, V. A. Província Mantiqueira. In: MANTESSO-NETO, V.; BARTORELLI, A.; CARNEIRO, C. R.; BRITO NEVES, B. B. (Org.). Geologia do Continente Sul-Americano - evolução da Obra de Fernando Flávio Marques de Almeida. São Paulo: Beca, 2004. p. 203-235.

INSTITUTO BRASILEIRO DE GEOGRAFIA E ESTATÍSTICA. Recursos naturais e meio ambiente: uma visão do Brasil. Rio de Janeiro: IBGE, 1997. 208p. 
MACHADO FILHO, L.; RIBEIRO, M.; GONZALEZ, S R.; SCHENINI, C. A.; SANTOS NETO, A.; PALMEIRA, R. C.; PIRES, J. L.; TEIXEIRA, W.; CASTRO, H. E. F. Geologia. In: Projeto Radambrasil. Brasília: DNPM, 1983. v. 32. p. 27-304.

MEIS, M. R. M.; MOURA, J. R. S. Upper quaternary sedimentation and Hillslope evolution: southeastern Brazilian Plateau. American Journal Science, v. 284, n. 3, p. 241-254, 1984.

MELLO, C. L. Fácies sedimentares, arquitetura deposicional e relações morfoestratigráficas em um sistema de leques aluviais holocênicos: Aloformação Manso - médio vale do rio Paraíba do Sul (SP/RJ). 1992. 188 f. Dissertação (Mestrado) - Departamento de Geologia, Instituto de Geociências, Universidade Federal do Rio de Janeiro, 1992.

MELLO, C. L. Sedimentação e Tectônica Cenozóicas no Médio Vale do Rio Doce (MG, Sudeste do Brasil) e suas implicações na evolução de um sistema de lagos. 1997. 275 f. Tese (Doutorado) - Instituto de Geociências, Universidade de São Paulo, São Paulo, 1997.

MELLO, C. L.; FERRARI, A. L. Neotectônica. In: SIMPÓSIO NACIONAL DE ESTUDOS TECTÔNICOS, 9., 2003. Búzios. Apostila do curso de Neotectônica... Búzios: SBG, 2003. 35 p.

MELLO, C. L.; MOURA, J. R. S.; CARMO, I. O.; SILVA, T. M.; PEIXOTO, M. N. O. Eventos de sedimentação durante o Holoceno no médio vale do rio Paraíba do Sul (SP/RJ) - aloestratigrafia e datações por radiocarbono. In: CONGRESSO DA ABEQUA, 5., 1995, Niterói. Anais... Niterói, 1995. p. 193-197.

MELLO, C. L.; METELO, C. M. S.; SUGUIO, K.; KOHLER, H. C. Quaternary Sedimentation, Neotectonics and the Evolution of Doce River Middle Valley Lake System (Southeastern Brazil). Revista do Instituto Geológico, São Paulo, v. 20, n. 1-2, p. 29-36, 1999.

MODENESI-GAUTIERI, M. C.; HIRUMA, S. T.; RICCOMINI, C. Morphotectonics of a High Plateau on the Northwestern flank of the Continental Rift of Southeastern Brazil. Geomorphology, v. 43, p. 257-271, 2002.

MOURA, J. R. S.; MEIS, M. R. M. Contribuição à estratigrafia do Quaternário Superior no médio vale do Rio Paraíba do Sul - Bananal, SP. Anais da Academia Brasileira de Ciências, v. 58, n . 1, p. 89-102, 1986.
MOURA, J. R. S.; MELlO, C. L. Classificação Aloestratigráfica do Quaternário Superior da região de Bananal (SP/RJ). Revista Brasileira de Geociências, v. 21, n. 3, p. 236-254, 1991.

PEIXOTO, M. N. Evolução do Relevo, Coberturas Sedimentares e Formação de Solos em Superficies Geomorfológicas - Médio vale do Rio Paraíba do Sul (SP) $R J)$. 2002. 198 f. Dissertação (Mestrado) - Departamento de Geografia, Instituto de Geociências, Universidade Federal do Rio de Janeiro, Rio de Janeiro, 2002.

RICCOMINI, C. O Rift Continental do Sudeste do Brasil. 1989. 304 f. Tese (Doutorado) - Instituto de Geociências, Universidade de São Paulo, São Paulo, 1989.

RICCOMINI, C.; ASSUMPÇÃO, M. Quaternary Tectonics in Brazil. Episodes, v. 22, n. 3, p. 221-225, 1999.

RICCOMINI, C.; PELOGGIA, A.; SALONI, J.; KOHNKE, M.; FIGUEIRA, R. Neotectonic activity in the Serra do Mar rift system (southeastern Brazil). Journal of South American Earth Sciences, v. 2, p. 191-197, 1989.

RICCOMINI, C.; SANT'ANNA, L. G.; FERRARI, A. L. Evolução geológica do Rift Continental do Sudeste do Brasil. In: MANTESSO-NETO, V.; BARTORELLI, A.; CARNEIRO, C. D. R; BRITO NEVES, B. B. (Org.). Geologia do Continente Sul-Americano: evolução da obra de Fernando Flávio Marques de Almeida. São Paulo: Beca, 2004. p. 383-405.

SADOWSKI, G. R.; CAMPANHA, G. A. C. Grandes Falhas no Brasil Continental. In: MANTESSO-NETO, V.; BARTORELLI, A.; CARNEIRO, C. D. R; BRITO NEVES, B. B. (Org.). Geologia do Continente SulAmericano: evolução da obra de Fernando Flávio Marques de Almeida. São Paulo: Beca, 2004. p. 407-421.

SALVADOR, E. D. Análise tectônica do vale do Rio Paraiba do Sul compreendida entre Cruzeiro (SP) e Itatiaia (RJ). 1994. 129 f. Dissertação (Mestrado) Instituto de Geociências, Universidade de São Paulo, São Paulo, 1994.

SALVADOR, E. D.; RICCOMINI, C. Neotectônica da região do alto estrutural de Queluz (SP-RJ, Brasil). Revista Brasileira de Geociências, v. 25, n. 3, p. 151-164, 1995.

SANSON, M. S. R. Sistemas deposicionais aluviais e tectônica rúptil cenozóica na região de Volta Redonda (RJ) - Rift Continental do Sudeste do Brasil. 2006. 
142 f. Dissertação (Mestrado) - Departamento de Geologia, Instituto de Geociências, Universidade Federal do Rio de Janeiro, Rio de Janeiro, 2006.

SARGES, R. R. Morfologia de lagos da região do médio Vale do Rio Doce..Minas Gerais, e a sua relação com a tectônica quaternária. 2002. 188 f. Dissertação (Mestrado)

- Departamento de Geologia, Instituto de Geociências, Universidade Federal do Rio de Janeiro, Rio de Janeiro, 2002.

SILVA, T. M. A estruturação geomorfológica do estado do Rio de Janeiro. 2002. 265 f. Tese (Doutorado) - Departamento de Geografia, Instituto de Geociências, Universidade Federal do Rio de Janeiro, Rio de Janeiro, 2002.

SILVA, T. M.; FERRARI, A. Controle tectônico da compartimentação geomorfológica no segmento nordeste do Rift Continental do Sudeste do Brasil. In: SIMPÓSIO DE GEOLOGIA DO SUDESTE, 5., 1997, Penedo. Atas... Penedo: SBG-RJ/ES/SP, ABGE, 1997. p. 48-50.

SUGUIO, K. Geologia do Quaternário e mudanças ambientais: $($ passado + presente $=$ futuro?). São Paulo: Paulo's Comunicações e Artes Gráficas. 1999. 366 p.

VASCONCELOS, P. M.; BECKER, T. A.; RENNE, P. R.; BRIMHALL, G. H. Age and duration of weathering by ${ }^{40} \mathrm{~K}-{ }^{40} \mathrm{Ar}$ analysis of potassium-manganese oxides. Science, v. 258, p. 451-455, 1992. 
